\title{
Prensa católica y sociedad en la construcción de la Iglesia argentina en la segunda mitad del siglo XIX
}

\author{
Miranda Lida \\ CONICET-Universidad Torcuato Di Tella
}

Este artículo repasa a grandes trazos el proceso de construcción de la Iglesia Católica en la Argentina en la segunda mitad del siglo XIX. En particular, se concentra en el papel que tuvieron las asociaciones de fieles vinculadas a las parroquias en el fomento del culto. También la prensa habría jugado un papel de relevancia promoviendo distintas iniciativas que redundaban en una mayor consolidación de la institución eclesiástica. Los fieles, la sociedad y la prensa reclamaron la necesidad de más sacerdotes, más parroquias, mejores templos y una mejor atención pastoral. Tuvieron una intensa participación que se quiere recoger en estas páginas.

PALABras ClaVe: Iglesia Católica, prensa católica, asociaciones, siglo XIX.

This article studies the period of construction of the Catholic Church at Argentina, in the second half of the nineteenth century. Specially it focuses on the role played by several associations related to parishes, that worked intensely on the benefit of the Church. Also the catholic press played a significant role promoting several campaigns in order to construct the Church. The society, the press and the associations of believers worked on the benefit of the parishes and claimed for a pastoral development. We attempt to reflect this effort on this article.

KeYwords: Catholic Church, Catholic press, Associations, XIX Century.

En la historiografía religiosa que sucedió al Concilio Vaticano II, la tesis de la romanización ha sido utilizada con frecuencia para abordar la historia de la Iglesia, desde la segunda mitad del siglo XIX en adelante. ${ }^{2}$

1 Agradezco a Luis Alberto Romero y a Roberto Di Stefano la discusión de algunas ideas que presento en este artículo.

2 Para una perspectiva amplia que comprende en sentido comparativo distintas experiencias latinoamericanas, véase Dussel, Enrique: "La Iglesia en el proceso de la organización nacional y de los estados en América Latina, 1830-1880", en Matute, Álvaro; Trejo, Evelia y Connaughton, Brian (coords.): Estado, Iglesia y sociedad en México. Siglo XIX, Miguel Ángel Porrúa, México, 1995. Para el caso argentino, y entre los trabajos más recientes véase Di Stefano, Roberto y Zanatta, Loris: 
Esta idea daba cuenta de una serie de procesos que afectaban a la Iglesia universal, en primer lugar, y repercutían luego en la manera en que se pensaba la historia de las iglesias nacionales. En pocas palabras, por romanización se entiende habitualmente un proceso mediante el cual el papado fue concentrando un poder en la Iglesia cada vez más omnímodo que se verificaba en distintas esferas y atribuciones: en lo dogmático, en el derecho eclesiástico (a fines del siglo XIX, León XIII sentó las bases que más tarde hicieron posible el primer Código de Derecho Canónico de 1917), en la disciplina del clero cada vez más estricta gracias a la codificación eclesiástica, en la liturgia y en la regulación de las atribuciones que les correspondían a los laicos. No fue un proceso lineal ni sencillo; las tendencias que se anunciaron con fuerza ya desde el pontificado de Pío IX no se verificaron en cada una de estas áreas al mismo tiempo. Pero de cualquier forma este proceso tuvo sus hitos, entre los que se cuentan: la condena a Lamennais por parte de Gregorio XVI en 1832, la declaración de la infalibilidad pontificia por el Concilio Vaticano I, el Motu proprio de Pío X de 1903 que uniformó la liturgia sobre la base del canto gregoriano, la condena al modernismo en nombre de un tomismo cada vez más ortodoxo —obra, ella también, de Pío X-, la creación de la Acción Católica por Pío XI.

En fin, la imagen que resulta de todo este proceso complejo y multidimensional es la de una Iglesia cada vez más piramidal, centralizada y jerárquica, donde el grueso de las decisiones se deposita en el papado. Con esta imagen construida por la idea de la romanización, se ha abordado el estudio de la Iglesia argentina. Fue necesario, entonces, identificar los hitos que hacían a la historia argentina de la romanización, entre los que se destacan, en las décadas finales del siglo XIX, la creación del Colegio Pío Latinoamericano (1858) donde fue a estudiar buena parte de los clérigos que en los años sucesivos pasarían a ocupar las jerarquías eclesiásticas de la Iglesia argentina, la convocatoria al Concilio Plenario Latinoamericano (1899) que tenía como objeto uniformar la discipli-

Historia de la Iglesia argentina. Desde la conquista hasta fines del siglo XX, Buenos Aires, 2000; también Zanatta, Loris: "De la libertad de culto posible a la libertad de culto verdadera. El catolicismo en la formación del mito nacional argentino, 1880-1910", en Carmagnani Marcello (ed.): Constitucionalismo y orden liberal (1850-1920), Torino, 2000, págs. 155-199. Para la historiografía francesa, puede verse por ejemplo Langlois, Claude: "Politique et religion", Philippe Joutard, Histoire de la France religieuse. Du roi très Chrétien à la laïcité républicaine XVIIIe-XIXe siècle, Éditions du Seuil, Paris, 2001, págs. 95-124. 
na eclesiástica, la regularización de las relaciones con la Santa Sede en $1900 .^{3}$

En suma, si bien esta tesis le atribuye a la Santa Sede un papel decisivo en el difícil proceso de construcción y consolidación institucional de la Iglesia argentina, no será ésta la perspectiva desde la cual abordaremos este mismo problema en las siguientes páginas: en lugar de atribuirle a la Santa Sede un papel privilegiado en la construcción de la Iglesia, pondremos énfasis en cambio en el modo en que participaron en este proceso tanto la sociedad y la prensa católica, como el Estado. ${ }^{4}$

Abordaremos cada uno por separado. Comenzaremos por considerar el papel que jugó el Estado y por destacar el esfuerzo que emprendió, pese a todas sus dificultades, en pos de construir una Iglesia nacional en la Argentina, luego de la caída de Rosas. Fue Urquiza quien se encargó de imprimirle a la Iglesia un carácter piramidal, tratando de apuntalar las jerarquías diocesanas; desde el Estado, Urquiza contribuyó a moldear una Iglesia nacional y centralizada, aun con todas sus dificultades, y ya no fragmentada en diversas iglesias provinciales, como había ocurrido durante la primera mitad del siglo XIX, al ritmo de las crisis políticas. ${ }^{5}$ Pero una vez superada la secesión entre Buenos Aires del resto del país —organizado políticamente bajo la confederación (1852 y

3 Hubo otros problemas que no consideraremos en esta historia de la romanización de la Iglesia argentina porque permanecieron pendientes de resolución hasta el siglo XX y por lo tanto exceden los límites de nuestro trabajo: el disciplinamiento del laicado, del clero y del episcopado, la creciente uniformidad ideológica que aportaría el tomismo. Han sido abordados por diversos autores: Zanatta, Loris: Del estado liberal a la nación católica. Iglesia y Ejército en los orígenes del peronismo, Universidad Nacional de Quilmes, 1996; Bianchi, Susana: "La conformación de la Iglesia católica como actor político-social: el episcopado argentino 1930-1960", en Bianchi, S. y Spinelli, M. E.: Actores, proyectos e ideas en la Argentina contemporánea, Tandil, 1997, págs. 17-48; "La conformación de la Iglesia católica como actor político-social. Los laicos en la institución eclesiástica: las asociaciones de élites (1930-1960), Anuario IEHS, 17, 2002, págs. 143-161.

4 Al señalar el papel del Estado, no compartimos los criterios de la historiografía confesional argentina, que ha tendido a considerar al Estado como permanente amenaza para la independencia de la Iglesia (en este sentido, por ejemplo, ver las obras de Cayetano Bruno, Guillermo Furlong, Américo Tonda, entre otros). Bien distinto a ésta es, sin embargo, el trabajo de Di Stefano, Roberto: El púlpito y la plaza. Clero, sociedad y política de la monarquía católica a la república rosista, Buenos Aires, 2004 que ha puesto el énfasis en el papel del Estado provincial como constructor de la Iglesia, en el marco del Estado de Buenos Aires durante las primeras décadas del siglo XIX. También, este tema ha sido tratado por Santamaría, Daniel: "Estado, Iglesia e inmigración en la Argentina moderna", Estudios Migratorios Latinoamericanos, 14, 1990, págs. 139-181.

5 No me voy a detener aquí en señalar los motivos por los cuales Urquiza se esforzó por construir la Iglesia dado que los he estudiado en: "Una Iglesia a la medida del Estado: la formación de la Iglesia nacional en la Argentina 1853-1865”, Prohistoria, en evaluación. 
1861)—, Buenos Aires se integró al orden nacional en 1862 trayendo consigo una lógica distinta en lo que hace a la construcción de la Iglesia en la que habría de destacarse la sociedad como su principal artífice. ${ }^{6}$ Sea el Estado o la sociedad quien construya la Iglesia, son pues en cada caso dos lógicas distintas que no conviven con suma facilidad. En Buenos Aires, en particular, el contraste entre ellas será evidente. Una prueba de ello la podemos hallar en la actitud de Leandro N. Alem a la hora de debatir en la Cámara de Diputados qué papel le tocaba al Estado en la construcción de la Iglesia y el sostenimiento del culto: en sus propias palabras, "el pueblo argentino es católico. Así será. Y por lo mismo es una ofensa hecha al catolicismo argentino declarar que sin la subvención del Estado quedaría la religión abandonada". ${ }^{7}$ Si el Estado se abocaba por sí solo a construir la Iglesia, a la sociedad no le quedaba mucho por hacer y su iniciativa quedaba completamente coartada; era éste, sin duda, un argumento liberal, pero no por ello anticlerical. ${ }^{8} \mathrm{Y}$ los que sostenían una tesis contraria a ésta, como es el caso de Félix Frías, claro está, depositaban en el Estado toda iniciativa. ${ }^{9}$ Nótese que, en uno u otro caso, el papel de la Santa Sede en la construcción de la Iglesia argentina ni siquiera se menciona.

Cuando decimos en este contexto "la sociedad" nos referimos a los propios vecinos que en cada parroquia y en cada pueblo de la provincia de Buenos Aires se asociaban en distintas organizaciones y comisiones vecinales —efímeras las más de las veces - con el simple propósito de construir un templo para el barrio, pueblo o localidad; y una vez construido, se organizaban nuevamente ya sea para ornamentarlo, mantenerlo en su debida "decencia" o simplemente llevar a cabo las diversas funciones religiosas con el debido decoro. En un período en el que se desarrolla la vida asociativa en distintos ámbitos, la Iglesia no permanece al margen de este

6 De allí las particularidades que presenta la relación entre la Iglesia y el Estado en la segunda mitad del siglo XIX. Al respecto véase Lida, Miranda: "De los recursos de fuerza o de las transformaciones de la Iglesia y del Estado en la segunda mitad del siglo XIX", Boletín del Instituto de Historia Argentina y Americana Dr. Emilio Ravignani, en evaluación.

7 Sesión del 15 de septiembre de 1877, Diario de sesiones de la Cámara de Diputados, Buenos Aires, 1877, pág. 871.

8 Acerca de las raíces whig de las ideas políticas de Alem véase Botana, Natalio y Gallo, Ezequiel: De la república posible a la república verdadera (1880-1910), Ariel, Buenos Aires, 1997; Alonso, Paula Entre la revolución y las urnas. Los orígenes de la Unión Cívica Radical y la política argentina en los años 90, Universidad de San Andrés, Buenos Aires, 2000.

9 Frías, Félix: "Dotación del clero", El Orden, 19 de octubre de 1855. 
proceso $;^{10}$ es precisamente en la segunda mitad del siglo XIX cuando el laicado, y la sociedad en sentido amplio, se organizan en diversas asociaciones que habrán de diferir ya de las antiguas cofradías coloniales. ${ }^{11} \mathrm{Y}$ muchas de ellas, como veremos, asumirán explícitamente la tarea de construir la Iglesia: así el caso de la multiplicidad de comisiones vecinales de cada parroquia que se organizan para recolectar fondos para erigir un altar, ensanchar un templo o construirlo directamente desde el inicio, sin esperar de ningún modo que el Estado tome la iniciativa en este proceso. En cada capilla, en cada parroquia, las asociaciones voluntarias florecían. Y en este contexto, la prensa católica jugó un papel decisivo que no se agotaba en su dimensión política e ideológica ${ }^{12}$; la prensa católica se desarrolló y creció a la par del desarrollo de la vida asociativa, y acompañó a su vez el proceso de construcción de la Iglesia, como veremos.

La construcción de la Iglesia encuentra distintos instrumentos en la segunda mitad del siglo XIX. Uno de ellos y quizás el principal, al menos para el Estado, era la confección del presupuesto de culto que anualmente sancionaría el Congreso desde $1853 .{ }^{13} \mathrm{El}$ presupuesto de culto ha recibido en la historiografía religiosa una valoración por lo común negativa dado que ha servido de medida para demostrar el escaso interés que el Estado "liberal" le adjudicaba a la Iglesia y en este sentido se ha puesto de relieve la mezquindad del Estado, por momentos aguda, de acuerdo con sus críticos, a la hora de atender el culto ${ }^{14}$. Sin embargo, no se ha estudiado cuáles

10 Acerca de las formas de organización de los porteños para la participación pública véase Sábato, Hilda: La política en las calles. Entre el voto y la movilización, 1862-1880, Buenos Aires, 1998; y de la misma autora "La vida pública en Buenos Aires", Liberalismo, Estado y orden burgués. Nueva historia argentina, vol. IV, Buenos Aires, 1999. También González Bernaldo, Pilar: "Los clubes electorales durante la secesión del Estado de Buenos Aires 1852-1861)", en Sábato, Hilda (coord.): Ciudadanía política y formación de las naciones. Perspectivas históricas de América Latina, México, 1999.

11 Di Stefano, Roberto: "Orígenes del movimiento asociativo: de las cofradías coloniales al auge mutualista 1776-1860", De las cofradías a las organizaciones de la sociedad civil. Historia de la iniciativa asociativa en la Argentina, 1776-1990, Buenos Aires, 2002. También, Ussher, Santiago: Cien años de acción católica, Buenos Aires, 1957.

12 En este sentido nuestra interpretación no coincide con la de Néstor Tomás Auza en su obra: Católicos y liberales en la generación del ochenta, Buenos Aires, 1981.

13 En Buenos Aires, el presupuesto de culto databa a nivel provincial de 1822, momento en que se suprimieron los diezmos. Si bien con algunas modificaciones, los diezmos sobrevivieron en buena parte de las provincias del interior, hasta ser suprimidos definitivamente en 1853.

14 El presupuesto de culto no ha sido estudiado cualitativamente, prestando atención a qué partidas se le asigna importancia, si se distribuye entre el alto y el bajo clero por igual, su distribución regional, entre otros ítems. Sólo se ha estudiado en conjunto, midiendo el porcentaje que ocupa en el presupuesto global del Estado, y utilizando esta medida como parámetro para determinar si tal o cual 
eran los argumentos que sostenían las decisiones estatales en torno al presupuesto de culto; si bien no nos detendremos aquí en un estudio pormenorizado de este punto, trataremos de señalar qué concepciones del Estado, de la Iglesia y de la sociedad se pueden hallar en torno a esto. El problema es, desde nuestra perspectiva, decisivo porque cuanto más cuantioso sea el presupuesto de culto, y más importante se lo considere para la construcción de la Iglesia, menor será el margen que se le deja a la sociedad para organizarse en asociaciones destinadas a desarrollar y fomentar el culto. En este sentido destacaremos que en 1853 nacieron, en la Confederación por un lado y en Buenos Aires por el otro, dos concepciones distintas acerca de qué debe ser el presupuesto de culto y quién deba ser en definitiva el que se dedique a construir la Iglesia: el Estado o la sociedad.

En la Confederación se adoptó el criterio de que el flamante presupuesto de culto debía favorecer a todos aquellos que hasta 1852 habían recibido retribuciones provenientes del cobro de diezmos, pero éste no era un criterio nada claro en realidad, dado que la distribución de los diezmos había variado de provincia a provincia, en especial, desde la crisis de $1820^{15}$. De cualquier forma, podemos señalar algunas particularidades: en la Confederación se dice que cuando se le asigna una renta al clero se le está asignando un sueldo, de tal modo que se considera al ingreso de los clérigos —en particular los de las iglesias catedrales - como si se tratara de cualquier otro sueldo de la administración y se considera, además, al clero como funcionario del Estado ${ }^{16}$; la Confederación por otra parte presenta un presupuesto de culto omnicomprensivo que contempla no sólo el sostenimiento de las sedes episcopales, sus respectivos cabildos eclesiásticos y seminarios, sino que además a ello se le suma una partida destinada a la construcción de las iglesias catedrales — vale decir, su edificación y ornamentación — y otra más destinada a los gastos de la curia; ${ }^{17}$ más aún,

gobierno favoreció o entorpeció el desarrollo institucional de la Iglesia. Descartaremos aquí esta perspectiva. Acerca del presupuesto de culto en la Argentina la bibliografía es escasa, pero pueden consultarse los trabajos de Udaondo, Enrique: Antecedentes del presupuesto de culto en la República Argentina, Buenos Aires, 1949; Maeder, Ernesto: "Breve historia del presupuesto de culto", Criterio, 2176, 1996; Rottjer, Aníbal: El presupuesto de culto en la Argentina, Buenos Aires, 1958.

15 Auza, Néstor Tomás: "Los recursos económicos de la Iglesia hasta 1853. Antecedentes del presupuesto de culto", Revista Histórica, 8, 1981.

16 El 23 de junio de 1856 se presentaba en el congreso de Paraná un proyecto que establecía la escala de los "sueldos y pensiones de las iglesias catedrales". Véase el diario de sesiones: Cámara de Senadores. Actas de sesiones de Paraná. 1856, Buenos Aires, 1886, pág. 76 y ss.

17 Véase la sesión del 6 de agosto de 1858 en Cámara de Diputados. Actas de las sesiones del Paraná correspondientes al año de 1858, Buenos Aires, 1886, pág. 634. 
Urquiza decidió por cuenta propia elaborar un proyecto de ley, luego aprobado por el Congreso, en el cual se les asignaba una partida a los párrocos de las iglesias matrices de toda la Confederación que pasaron a gozar "del sueldo de seiscientos pesos anuales". ${ }^{18}$ A pesar de las múltiples dificultades financieras por las que atravesó la Confederación, el Estado no vaciló en los años de Urquiza en ser generoso con el presupuesto destinado a la Iglesia. Más todavía, y es éste un punto que nos interesa destacar aquí, la iniciativa del Estado podía llegar al punto de sustituir a la de los particulares: cuando un particular decidió traer al país a religiosos misioneros italianos para que atendieran las fronteras de Salta, Urquiza no se quedó atrás, decidió compensar económicamente a quien había tomado la iniciativa y se le pagó un monto por su gestión ${ }^{19}$. ¿A qué se debe tanta generosidad para con la Iglesia y, en especial, el clero secular de la Confederación? No era ésta materia de fe, sino una cuestión política: la Iglesia era un problema político de primer orden que merecía la atención del gobierno porque la secesión había dejado "huérfanas" a las provincias del litoral que dependían en lo eclesiástico de Buenos Aires y la Confederación no estaba de ningún modo dispuesta a admitir que los párrocos del litoral rindieran obediencia a un obispo, ante todo, porteño. Este problema fue advertido con toda claridad por Urquiza, por su ministro de culto Facundo Martínez Zuviría que hicieron gestiones ante la Santa Sede, muchas de ellas exitosas, y obtuvieron que la Confederación contara con un delegado romano que le concedió a la diócesis de Paraná, establecida en 1860, gran cantidad de privilegios. El Estado le prestó enorme atención a las materias eclesiásticas y evitó dejar librada a la iniciativa particular la construcción de la Iglesia; su presencia en este sentido se hizo notar con fuerza a tal punto que el presupuesto estatal de culto llegó a ocupar en los años de Urquiza el 13\% del presupuesto estatal. ${ }^{20}$

$18 \mathrm{Si}$ bien el sueldo no era holgado - equivalía a lo que cobraba un racionero en cualquier catedral de la Confederación-, hay que considerar que los párrocos percibían además los derechos parroquiales. Véase la iniciativa de Urquiza en la sesión del 26 de junio en la Cámara de Diputados. Actas de las sesiones del Paraná correspondientes al año de 1857, Buenos Aires, 1885, pág. 89 y ss.

19 Se trata del caso de Isidoro Fernández, a quien se lo compensó con la suma de 2639 pesos. Véase la sesión del 27 de junio en Cámara de Senadores. Actas de las sesiones del Paraná correspondientes al año de 1857, Buenos Aires, 1885, pág. 66 y ss.

20 En 1855 el presupuesto de culto de la Confederación era de 130991 pesos, mientras que el presupuesto total sumaba 1001628 pesos, lo cual representa el 13,07\%. Véase el presupuesto en Cámara de Senadores. Actas de las sesiones del Paraná correspondientes al año de 1855, Buenos Aires, 1883, págs. 233-4. 
Buenos Aires recibió en 1862 la herencia de Urquiza, pero Mitre no permaneció fiel a ella: se encargó de deshacerse de Marino Marini, el delegado de la Santa Sede que había sido traído por Urquiza, que quería elevar a la ciudad de Paraná al rango de arzobispado y, en sentido contrario, gestionó que la primera arquidiócesis argentina tuviera su sede en Buenos Aires, que fue establecida en 1865. Puede verse, pues, cómo el Estado nuevamente juega una vez más un papel de primer orden en la construcción de la Iglesia nacional. Sin embargo, el presupuesto estatal de culto no fue de ningún modo comparable al que le había asignado Urquiza: apenas rondaba el $2 \%$ del presupuesto del Estado. ${ }^{21}$ Pero lo importante del caso es que el contraste está no sólo en los montos que el presupuesto de culto alcanza, sino ante todo en la concepción que de él se tiene. Lo que ocurrirá con Mitre es, pues, un fuerte proceso por el cual el Estado le abrirá el camino a la sociedad en el transcurso de la construcción de la Iglesia, de tal modo que el Estado tenderá a reducir las partidas destinadas al culto precisamente con el propósito de que los gastos de culto corran por cuenta de los propios fieles y de las municipalidades locales.

Ya a partir de los años '50, los debates en torno al presupuesto de culto de Buenos Aires y el modo en que éste es concebido reflejarán las concepciones liberales en las que se sustenta. Lo que está en juego es una concepción puramente liberal aunque no necesariamente anticlerical: se considera que si el Estado se hace cargo del proceso de construcción de la Iglesia, a la sociedad —en particular, a los vecinos y los fieles- no le quedaría nada por hacer. Es, en fin, un argumento que ante todo riñe con el Estado, más que con la propia religión. Veamos algunos rasgos del presupuesto de culto tal como se adoptó en Buenos Aires en la década de 1850, rasgos que habrán de perdurar luego de $1862 .{ }^{22}$

En primer lugar, debemos destacar que no se concebía a los clérigos como funcionarios del Estado y las retribuciones que recibían no se las calificaba de ningún modo como un salario, sino más bien como subvenciones que le servían de auxilio: en este sentido, el Ministro de Gobierno afirmaría en 1856 en el Congreso que "no hay tal deber en el Estado de dar estos auxi-

21 En 1861, por ejemplo, el presupuesto total de culto de Buenos Aires sumaba 813800 pesos, mientras que el presupuesto total del Estado alcanzaba los 44596014 pesos, lo cual representa el 1,82\%. Véase el Diario de Sesiones de la Cámara de Senadores del Estado de Buenos Aires. 1861, Buenos Aires, 1863, págs. 162 y ss.

22 Al respecto véase Lida, Miranda: "El presupuesto de culto en la Argentina. Estado y sociedad ante el proceso de construcción de la Iglesia, 1853-1880", ponencia, XIX Jornadas de Historia Económica, San Martín de los Andes, octubre de 2004. 
lios", ${ }^{23}$ se sugirió incluso adoptar el modelo anglosajón en el cual los clérigos son financiados exclusivamente por los fieles y por la sociedad y, se concluye, que debería suprimirse en realidad toda partida destinada al culto, o al menos tender a reducirlas lo más posible (no es casual que Félix Frías acusara al Estado de Buenos Aires de no sostener el culto con el debido decoro). En segundo lugar, y dado que se considera al presupuesto de culto como un simple auxilio, este último habrá de variar de acuerdo con algunas consideraciones particulares: el auxilio será mayor allí donde la sociedad carezca de recursos (materiales y humanos) para sostener el culto; por ello curatos marginales que no hace poco tiempo atrás eran simplemente capellanías castrenses en la frontera de Buenos Aires habrán de recibir importantes subvenciones por parte del Estado provincial, no así el caso de los curatos de la ciudad que reciben a lo sumo auxilios mínimos..$^{24}$ De este modo, las partidas destinadas al clero parroquial no se distribuyen uniformemente a lo largo de todo el Estado de Buenos Aires, lo cual dejará el camino abierto para que desde cada parroquia se advierta la necesidad de los vecinos de organizarse para intentar presionar sobre el Estado. Otra de las características que presenta el culto en el Estado de Buenos Aires es que se le deja a los particulares absoluta libertad de acción en cualquier iniciativa destinada a atraer órdenes religiosas, rubro en el cual el Estado declina cualquier tipo de intervención, a diferencia de lo que ocurría, según vimos, en la Confederación; así puede verse un dictamen de Dalmacio Vélez Sársfield - que fue adoptado como norma por Buenos Aires- en el que afirma que los particulares pueden actuar en este rubro "sin necesidad de autorización especial por parte del Gobierno". ${ }^{25}$ No es casual que en 1862, a la hora de la organización nacional, Buenos Aires no haya admitido una completa "nacionalización" de su presupuesto de culto: si bien habrán de nacionalizarse las partidas destinadas al alto clero (obispado, seminario, curia y cabildo eclesiástico), la provincia conservará en sus manos las partidas destinadas a las parroquias de Buenos Aires que continuará asignando en cali-

23 Diario de sesiones de la Cámara de Senadores del Estado de Buenos Aires de 1856, Buenos Aires, 1856, sesión del 28 de octubre, pág. 533.

24 Así como a la parroquia de Balvanera se le quitaba en 1856 el auxilio que le otorgaba el Estado provincial porque se la consideraba en condición de bastarse con los aportes de sus feligreses (Diario de sesiones de la Cámara de Senadores del Estado de Buenos Aires de 1856, pág. 533), por otra parte en 1861 se le asignaba una importante partida al cura de Bahía Blanca, próximo a la frontera (Diario de sesiones de la Cámara de Diputados del Estado de Buenos Aires, 1861, pág. 162).

25 El dictamen se halla transcripto en Santiago Ussher, Las hermanas de la Misericordia irlandesas. Apuntes históricos sobre sus cien años en la Argentina 1856-24 de febrero-1956, Buenos Aires, 1955, págs. $128-132$. 
dad de auxilio, sin ser traspasadas a la nación. ${ }^{26}$ Dado que se trata simplemente de un auxilio y el sostenimiento del clero parroquial no es absorbido por el Estado nacional, la iniciativa de la sociedad en la construcción de la Iglesia no se ve disminuida, en especial a nivel local y parroquial.

Puede verse que en Buenos Aires el Estado le abrió el paso a la sociedad en la tarea de construir la Iglesia. Y la instalación del régimen municipal en Buenos Aires luego de la caída de Rosas hizo el resto. En 1854 se estableció la ley que regularía el régimen municipal, luego de largas décadas en las cuales se había carecido de autonomía en el poder local27; nos interesa destacar aquí que el artículo 63 de esta ley le confería a las municipalidades de campaña, entre otros deberes: "promover y consultar los intereses materiales y morales del partido con absoluta prescindencia de los intereses políticos. Por consecuencia propondrá cuantas medidas considere conducentes al mejor orden [...] en todos sus ramos [...] instrucción pública, establecimientos de beneficencia, culto divino". ${ }^{28}$ Esta ley sólo postuló un principio genérico que requirió ulterior reglamentación; así en 1856 el obispo Mariano Escalada establecía un reglamento para regular las relaciones entre las municipalidades de campaña y sus respectivos párrocos en el que le atribuyó al "Municipal encargado de la sindicatura de la iglesia", junto con el párroco y un vecino "distinguido", ${ }^{29}$ la administración del capital destinado a la "fábrica" de la iglesia parroquial: de tal modo que se le atribuyeron a las municipalidades de campaña y a los vecinos de cada localidad tareas que desde los años de Rosas habían quedado depositadas

26 Véase la disposición respectiva en la que se traspasa a la nación únicamente las rentas del alto clero, no así el clero parroquial: "Deslindando los objetos nacionales y provinciales del presupuesto de Buenos Aires y proveyendo a la garantía de él" datada el 3 de octubre de 1862, Registro oficial de la República Argentina que comprende los documentos espedidos desde 1810 hasta 1873, vol. IV, Buenos Aires, 1883, pág. 480.

27 Desde la supresión de los cabildos en 1821 los jueces de paz fueron designados por el gobierno de tal modo que no existía ningún tipo de autonomía local. Sin embargo la ley de 1854 dispuso que al juez de paz lo acompañarían en el gobierno local "cuatro propietarios vecinos del distrito", renovables anualmente. Sobre este tema, véase Ternavasio, Marcela: Municipio y política: un vínculo conflictivo. Análisis histórico de la constitución de los espacios locales en Argentina 1850-1920, tesis de maestría, Flacso, 1991; y de la misma autora, "La supresión del Cabildo de Buenos Aires: ¿crónica de una muerte anunciada?", Boletín del Instituto de Historia Argentina y Americana Dr. Emilio Ravignani, 21, 2000.

28 Véase la ley del 11 de octubre de 1854, reproducida en Evolución institucional del municipio de la Ciudad de Buenos Aires, Buenos Aires, Concejo Deliberante, 1963.

29 Cuando se dice "vecino" se hace referencia a los contribuyentes, de tal modo que no es un criterio de igualdad política el que aquí prevalece. Éste era un rasgo típico, según sostiene Luciano de Privitellio, del municipio decimonónico. Véase Vecinos y ciudadanos. Política y sociedad en la Buenos Aires de entreguerras, Buenos Aires, 2003, págs. 23-28. 
exclusivamente en las manos del párroco..$^{30}$ Sobre estas bases, pues, las municipalidades locales y los vecinos jugarán un papel decisivo en la construcción de la Iglesia, en particular en Buenos Aires y su campaña, como veremos a continuación.

Cuando cayó Rosas, los pueblos de campaña descubrieron que el templo de su localidad —en aquellos casos en que lo tuvieran — les resultaba chico, incómodo y mal construido, se inició entonces un vasto proceso o bien de reedificación de las antiguas parroquias y capillas de campaña, o bien de construcción ex nihilo en los nuevos pueblos que se conformaron luego de $1852 .{ }^{31}$ De cualquier modo, el movimiento en este sentido es notorio. En algunas parroquias ocurría que el viejo templo comenzó a contrastar con los nuevos edificios que se estaban construyendo al ritmo del crecimiento económico, fruto de la expansión del lanar y esto era considerado una afrenta para la imagen del pueblo: en este sentido, el juez de paz de Lobos declararía en 1853 que necesitaba un nuevo "templo amenizando con la clase de edificios que hay y que diariamente se construyen", dado que el antiguo, según declaraba, tenía techos de paja y no se encontraba a la altura de las circunstancias. ${ }^{32}$ Por su parte, el cura de Dolores consideraba en 1852 que era "sumamente desdoroso el carecer de ese religioso edificio en la época especialmente en que florecía su comercio". ${ }^{33}$ En otros casos, ocurría que un pueblo de campaña no toleraba quedarse atrás cuando advertía que una localidad vecina había logrado embellecer el templo al punto de atraer a las principales familias de otros pueblos, de tal modo que aquellos que no habían emprendido ninguna refacción se veían súbitamente despoblados, en especial los días domingo cuando los feligreses preferían viajar hasta el templo del pueblo vecino: "¿No es bochornoso — se preguntaba un vecino de Mercedes en 1876- que pueblos de la provincia de

30 "Reglamento para las relaciones entre las municipalidades y los curas de campaña en la parte relativa al culto, establecido por Mariano José Espinosa y aprobado por Dalmacio Vélez Sársfield como fiscal del Estado el 17 de julio de 1856", Registro oficial del Estado de Buenos Aires, Buenos Aires, 1856, pág. 69 y ss. Este reglamento daba marcha atrás con el decreto de Rosas del 26 de abril de 1830, "Se restituye la administración de los fondos de fábrica a los párrocos", Registro oficial del Gobierno de Buenos Aires, 5, libro 9, págs. 4-5. Acerca de la significación de este decreto véase Di Stefano: El púlpito y la plaza...

31 La significación de este proceso ha sido advertida por la prensa de la época. Véase Correa, Fray Olegario: "Reparo de los templos", La Religión, 28 de enero de 1854.

32 Véase la nota dirigida por el juez de paz de Lobos al Ministro de Gobierno del Estado de Buenos Aires Ireneo Portela del 23 de noviembre de 1853 en AGN, Estado de Buenos Aires, X-28-46,5420 .

33 Nota dirigida por el párroco de Dolores al ministro de Gobierno Valentín Alsina, 12 de marzo de 1852, AGN, Estado de Buenos Aires, X-28-1-4, 265. 
Buenos Aires que no gozan de la nombradía del de Mercedes en todo y por todo tengan el orgullo de poseer templos católicos que correspondan y hagan honor a sus habitantes? ¿Citaremos a lo dicho el templo de San Antonio de Areco, el de Barracas al Sud, el de San Vicente, de Las Flores y tantísimos otros?". Sin duda la situación era bochornosa para quien escribía estas líneas, pero su autor no tardaría en proponer el modo de salir de ella: "¿nuestra Municipalidad no podrá cooperar, que tiene unas entradas tan pingües, uniéndose con el vecindario y su partido, levantar un templo que engrandezca a esta ciudad, que es lo que da vida a los pueblos y no otras cosas?". ${ }^{34}$ Especialmente en la campaña la construcción del templo involucraba la propia "identidad", bien podríamos decir, de cada pueblo, aquello que permitía distinguirlo de su vecino; de ahí que las comparaciones no sólo fueran habituales entre los vecinos sino que también aparecían reflejadas en la prensa, a la hora de informar acerca de las nuevas obras. ${ }^{35}$ Pero en definitiva, la comparación más anhelada era con Buenos Aires: estar a la altura de la ciudad era la máxima aspiración de los pueblos de la campaña, y por ella se desvivían. ${ }^{36}$

Tener un templo bien construido y bien provisto era algo más que un motivo de orgullo para el pueblo; era también la imagen visible para cualquier pueblo que hubiera entrado en un franco proceso de crecimiento económico, de tal modo que no se concebía que el progreso material pudiera desarrollarse con independencia del progreso "moral" o "espiritual": en este sentido se puede leer en la prensa de la época que "la edificación de una iglesia católica propende al engrandecimiento moral del pueblo porque es una nueva cátedra de doctrina [...] y tiende al progreso material porque es un nuevo ornato para la localidad". ${ }^{37}$ Así, cuando en 1857 el gobierno del Estado de Buenos Aires le solicitó a los jueces de paz que informaran acerca de las "mejoras que se hayan practicado en su partido", los respectivos informes contenían reseñas acerca del movimiento de la hacienda y de las cabezas de ganado, daban cuenta del crecimiento poblacional, de las indus-

34 "Correo de la campaña" (carta anónima, firmada por "un suscriptor”), La América del Sud. Diario católico, político, comercial y de intereses generales, 23 de febrero de 1876.

35 Por ejemplo, en 1877, a la hora de la inauguración de la capilla y el cementerio de Balcarce, La América del Sud indicaba que "según testigos fidedignos ni en el Tandil ni en Ayacucho tienen cosa igual", "Partido de Balcarce", 15 de agosto de 1877.

36 Por ejemplo, en 1879 se elogiaba que en el pueblo de San José de Flores, a la hora de la colocación de la piedra fundamental de una capilla, se logró alcanzar en la ceremonia la "elegancia y la gracia porteña", "La capilla de San Luis", La América del Sud, 28 de junio de 1879.

37 “San José de Flores”, La América del Sud, 26 y 27 de enero de 1880. 
trias y comercios que se establecían en cada localidad, de las mejoras edilicias, sin omitir de ningún modo una consideración acerca del estado del templo y las refacciones que en él se hubieran hecho, o se planeaban hacer. ${ }^{38}$ No es casual entonces encontrar que en aquellos lugares donde se está construyendo el pueblo desde cero, que el templo forme parte central de ese proceso de construcción: construir el pueblo comprende simultáneamente la construcción de una capilla, una escuela y la casa municipal. ${ }^{39}$ En la ciudad en cambio, la construcción del templo puede encontrarse estrechamente vinculada a la construcción del espacio urbano: en 1854 la comisión de vecinos encargada de las obras de refacción del templo de La Piedad declaraba que no sólo estaba preocupada por la refacción del atrio y una serie de obras en el interior del templo, sino que además había "invertido a más de algunos miles de pesos para contribuir al empedrado de las dos calles del frente". ${ }^{40}$

Los motivos, pues, para que los vecinos y las municipalidades se involucraran en la construcción de un templo eran variados, de acuerdo con las múltiples circunstancias de cada localidad de Buenos Aires, ya sea en la ciudad o en la campaña; pero de todos modos vale la pena subrayar que la preocupación por tener un templo no era una simple cuestión "religiosa" sino que involucraba la construcción de los pueblos de campaña y de la ciudad. Y los propios vecinos lo concebían de este modo: así como se organizaban en comisiones para construir el templo, levantar un altar, adquirir un órgano, una pintura o bien organizar la fiesta religiosa del patrono de la localidad, se organizaban de igual modo para otras obras consideradas de utilidad pública como podía ser la construcción de caminos y puentes. ${ }^{41}$ En

38 Los informes enviados en 1857 por los jueces de paz de cada partido de campaña al gobierno se encuentran en AGN, Estado de Buenos Aires, X-28-10-8, 13213.

39 Un ejemplo de este proceso es el caso de Chivilcoy, donde varios vecinos organizan la construcción simultánea de municipio, templo y escuela. Véase Birabent, Mauricio: El pueblo de Sarmiento. Chivilcoy desde sus orígenes hasta 1880, Buenos Aires, 1935, pág. 65.

40 Nota dirigida por la comisión de vecinos del templo de La Piedad a Valentín Alsina, 8 de febrero de 1856, AGN, Estado de Buenos Aires, X-28-8-12, 11654.

41 Dos ejemplos: se puede considerar nuevamente el caso de Chivilcoy, donde un vecino que participaba de la comisión destinada a levantar el templo se ocupó igualmente de las tareas topográficas requeridas para la fundación del pueblo (Birabent: El pueblo de Sarmiento..., pág. 70 y ss). Por otro lado, se pueden cotejar los apellidos de los vecinos que participaron en San José de Flores en la construcción de la "vía pública del Oeste" (AGN, Estado de Buenos Aires, X-28-4-6, 5416) con los apellidos de los vecinos que participaron en la construcción del templo en las décadas sucesivas en Carbia, Rómulo: San José de Flores. Bosquejo histórico 1609-1906, Buenos Aires, 1906; Miranda, Arnaldo Ignacio Adolfo: "Comisión para la obra del templo de San José de Flores. Sucinta referencia relativa a su desempeño", San José de Flores. Las instituciones del barrio, Junta de Historia de Buenos Aires, Buenos Aires, 1993. 
esta multiplicidad de obras, los párrocos no permanecían al margen, al igual que los vecinos se involucraban en las diversas empresas de construcción que el pueblo emprendía; así, no es casual que un párroco participe al mismo tiempo de una comisión pro templo y de una comisión vecinal destinada a la construcción de un puente o una escuela. ${ }^{42}$

Veamos más detenidamente cómo se llevaban a cabo estas obras. Tanto los principales vecinos — recordemos que la categoría de vecino se superponía a la de contribuyente - organizados en comisiones, como el sacerdote (en aquellos casos en que lo hubiera) y la municipalidad, junto con el respectivo juez de paz han jugado un papel decisivo en la construcción de los templos en Buenos Aires en la segunda mitad del XIX. ${ }^{43}$ A veces ni siquiera se le pedía al Estado que contribuyera con recursos. Como el caso de la creación de la parroquia de Barracas al Sud - y su respectivo templo_- cuyo juez de paz declaraba en 1852 que aquel pueblo "todo lo puede y lo hace sin gravar al Estado: que tiene una magnífica campaña; que se convertirán sus posesiones en bellezas agrícolas". ${ }^{44} \mathrm{Y}$ agregaba que las comisiones de vecinos ya se habían puesto en acción para recolectar "fondos voluntarios" entre los pobladores, con resultados exitosos, según declaraba. Semejante éxito, señalaba, sólo podía explicarse por la decidida participación de un grupo de inmigrantes vascos que deseaba, ante todo, contar con un sacerdote que hablara su lengua: "queremos elegir nuestro cura", añadía el juez de paz. No es difícil imaginar que el provisor de la diócesis de Buenos Aires se opusiera a semejante pedido; lo hizo alegando que la población de ese partido no estaba en condiciones de sustentar económicamente una nueva parroquia dado que la población con la que contaba estaba en su mayor parte compuesta por trabajadores temporarios que no podían garantizar la estabilidad de los ingresos parroquiales ni tampoco comprometerse a construir un templo. ${ }^{45}$ Fue necesaria la intervención del Estado en este punto, pero éste jugó simplemente un

42 Así ocurría con el cura de Las Conchas. Véase La América del Sud, 12 de febrero de 1879.

43 Por ejemplo, véase la historia de la parroquia de San Juan Evangelista que escribió Belza, Juan: En la boca del Riachuelo, Buenos Aires, Don Bosco, 1957, págs. 65 y ss; otro caso en el que los vecinos participan en la reedificación de una vieja parroquia bonaerense es el de San Isidro: véase Actis, Francisco: Historia de la parroquia de San Isidro y de su santo Patrono 1730-1930, Talleres Gráficos Institución Juan Segundo Fernández, s/f, cap. IX. Los ejemplos en este sentido podrían multiplicarse.

44 Véanse las notas del juez de paz de Barracas al Sud dirigidas al Gobierno el 8 de marzo y el 31 de mayo de 1852 en AGN, Estado de Buenos Aires, X-28-1-4.

45 Nota de Miguel García dirigida al Gobierno, 26 de octubre de 1853, AGN, Estado de Buenos Aires, X-28-1-4. 
papel de árbitro entre la municipalidad y la autoridad eclesiástica, obteniendo por parte de la municipalidad el compromiso de que ella se encargaría de garantizar las rentas del párroco convocando a los vecinos a fin de asignarle al cura una cuota mensual, en caso de que los aranceles parroquiales no resultaran suficientes: la parroquia fue así erigida en 1854. El Estado, simple árbitro, le dejaba a la sociedad el camino libre para que hiciera la Iglesia.

Los mecanismos que tenían los vecinos para obtener fondos eran múltiples: podían sencillamente apelar a los donativos en dinero, comprometiendo a la población a pagar cuotas mensuales, "levantando suscripciones" al efecto; ${ }^{46}$ el Estado no sólo las avalaba sino que las fomentaba en aquellos pueblos que aún no las hubieran iniciado. Así, en 1854 el Gobierno le recomendaba al juez de paz de San Andrés de Giles "exaltar el patriotismo del vecindario y sus propias conveniencias a efectos de obtener por medio de suscripciones la cantidad suficiente para la realización de la obra [...] este mismo proceder se observa en los demás partidos de campaña con el más completo éxito". ${ }^{47}$ Asimismo los vecinos podían obtener donativos en especie, ya sea la donación de los ladrillos u otros materiales de construcción destinados a las obras que eran cedidos por albañiles o por los dueños de los hornos de ladrillos, ${ }^{48}$ ya sea la ornamentación para el futuro templo, que podía provenir de una vieja capilla privada $^{49}$; podían además obtener a su favor mano de obra gratuita de peones y jornaleros que, a fin de no quedarse afuera del emprendimiento del pueblo en el cual querían participar a toda costa, cedían aquello que ellos tenían, vale decir, su propia fuerza de trabajo. Sin embargo, éstos eran recursos inestables, el resultado de una suscripción no podía preverse y no todos los pueblos contaban con quienes estuvieran en condiciones de ceder materiales de construcción; por otra parte, la mano de obra era inestable en la campaña, residía en un pueblo sólo por una temporada y no se

46 Los ejemplos en este sentido son numerosos: para construir el templo de San Andrés de Giles que estaba presupuestado en 530000, la Municipalidad contaba sólo con 150000 y el resto esperaba obtenerlos de una suscripción (García, Secundino Néstor: Historia de San Andrés de Giles desde sus orígenes hasta 1930, San Andrés de Giles, 1986, pág. 176); en Bragado, al igual que en muchos otros lados, la suscripción se llevó a cabo "con los auspicios de un núcleo de vecinos caracterizados" (Moya, Juan R.: Contribución a la historia de Bragado, La Plata, 1957, pág. 169).

47 Nota de Ireneo Portela, datada el 5 de junio de 1854, transcripta en García: Historia de San Andrés de Giles..., pág. 166 y ss.

48 Por ejemplo, en 1890 un albañil de San Isidro donó arena y otros materiales para la construcción del templo de Olivos. Véase "La capilla de Olivos", La Voz de la Iglesia, 12 de abril de 1890.

49 Véase Llanes, Ricardo: El barrio de San Cristóbal, Buenos Aires, 1970, pág. 23. 
podía garantizar su continuidad dado que el mercado de trabajo era móvil, inestable y fluido. ${ }^{50}$ Los ejemplos de los muy variados donativos que recibían los templos a la hora de su construcción son innumerables, pero sin duda se destacan aquellos que provenían de los vecinos más "caracterizados" de cada localidad por ser no sólo los más abundantes sino también los que ofrecían mayores garantías. Claro está que estos pocos vecinos "notables", que donan espontánea y voluntariamente cuantiosas sumas de dinero, son aquellos que habrán de liderar las comisiones pro-templo en su partido. ${ }^{51}$

Con el tiempo, las comisiones de vecinos idearon además otros mecanismos para obtener recursos, ya sea la organización de conciertos, a cargo de aficionados, es decir, los propios vecinos la más de las veces ${ }^{52}$; la puesta en escena de obras de teatro $;^{53}$ la organización de bazares y rifas de cuya gestión se encargaban por lo general las "principales" mujeres de la localidad: por ejemplo, en San Justo, "una sociedad de respetables matronas [...] se propone abrir un bazar de importantes objetos donados que se rifarán en beneficio de la obra del templo". ${ }^{54} \mathrm{Y}$ si la envergadura de la obra en curso lo justificaba, se podía incluso organizar un verdadero "festival" que incluyera una kermese que combinaba la feria, la música, el teatro, el bazar, las rifas, juegos, baile y otros entretenimientos — todo ello con el aval del arzo-

50 Este problema se presentó con toda su agudeza en el partido de Pergamino. Véase al respecto Giménez Colodrero, Luis E.: Historia del partido de Pergamino hasta 1895, Archivo Histórico de la Provincia de Buenos Aires, La Plata, 1945, pág. 201 y ss. Las particularidades del mercado de trabajo han sido estudiadas por Sábato, Hilda y Romero, Luis Alberto: Los trabajadores de Buenos Aires. La experiencia del mercado 1850-1880, Sudamericana, Buenos Aires, 1992.

51 Una nota del juez de paz de Lobos al gobierno declaraba el 23 de noviembre de 1853 que "cuenta [...] para dar principio a dicha obra con 51000 pesos que donan gustosísima y espontáneamente los ciudadanos expresados": se trata de los mismos que habrán de componer la comisión a cargo de las obras. Véase AGN, Estado de Buenos Aires, X-28-4-6, 5420. Otro caso en que coinciden los principales contribuyentes con los miembros de la comisión lo refiere "Templo de San Cristóbal", $L a$ Unión, 14 de agosto de 1887.

52 Véase "Concierto en San Fernando", La América del Sud, 26 de enero de 1877; "A beneficio de un templo", La América del Sud, 4 de diciembre de 1877 (donde se anuncia la realización de una "matinée musical, a cargo de aficionadas); también: "Bazar de caridad", La Unión, 17 de julio de 1887, donde se anuncia un concierto en el que participan "las principales niñas de la parroquia".

53 En la década de 1870 se popularizaron las obras de Fernández Espadero (Pureza y vicio y Las campanas del monasterio) que se solían representar en los pueblos de campaña. Sus obras, además, se difundían en El católico argentino que publicó un folletín de este mismo autor a partir de julio de 1875 .

54 "San Justo", La América del Sud, 3 de julio de 1877. Asimismo el 24 de septiembre de 1878 el mismo periódico anunciaba: "las damas de Belgrano preparan activamente un bazar cuyo producto se destina a las obras del templo de la localidad". Algo similar ocurría en el Pilar, La América del Sud, 11 de octubre de 1878 . 
bispo, por cierto-: así se hizo en 1898, a fin de juntar fondos nada menos que para el santuario de Luján. ${ }^{55}$

Y aquello que los vecinos no lograban por su cuenta, en materia de recursos, podía ser facilitado por la visita pastoral que el arzobispo realizaba periódicamente por los distritos de la campaña bonaerense. La visita del arzobispo no era simplemente un recurso con el que contaba la autoridad eclesiástica para disciplinar al clero parroquial ${ }^{56}$ por el contrario, muchas veces era solicitada por el propio párroco y por las comisiones de vecinos porque esperaban que con ella las contribuciones a la obra de la iglesia se acrecentaran. Que el arzobispo visitara una localidad de campaña era vivido por los pueblos como un verdadero "acontecimiento" capaz de atraer a pobladores de localidades vecinas y ello, esperaban, traería como consecuencia mayores contribuciones para las obras en marcha. Una ocasión extraordinaria para la visita de la autoridad eclesiástica era la fundación de un pueblo, la colocación de la piedra fundamental del templo o, más tarde, su bendición, que se convertían en verdaderas "fiestas", que, en verdad, de religioso tenían bastante poco. Por ejemplo, en 1856 el pueblo de Belgrano adquirió la carta de ciudadanía y se reinauguró su capilla luego de una serie de refacciones; para la ocasión se invitó al por entonces obispo Escalada fue elevado a arzobispo en 1865- a presidir la función religiosa que ocupó toda la mañana de aquel día y a ella le sucedió una serie de festejos que iban más allá de lo estrictamente religioso: "repiques de campanas, salvas de bombas, estallido de cohetes y petardos anunciaron que la ceremonia religiosa había terminado [...] Un refresco general había sido preparado por la Comisión en el patio de la iglesia [...] se había hecho asar también seis terneras con cuero con las que se obsequió al vecindario [...] el jamón y las sardinas [...] con sus correspondientes vinos circularon y alegraron los ánimos". ${ }^{57}$ En tales ocasiones, la presencia de la autoridad eclesiástica hacía de esa celebración un evento importante que, incluso, llegaba a hallar eco en la prensa.

En verdad, cualquier ocasión era buena para invitar al arzobispo a que visitara un pueblo de campaña pero, en especial, la celebración anual del patrono del templo, a las que la parroquias solían invitar al arzobispo... y si éste no se dignaba concurrir, cuando menos se solicitaba la visita de algún sacerdote de la ciudad a fin de que su presencia le confiriera a la función

55 Véase "Festival por el Santuario de Luján”, La Buena Lectura, 29 de enero de 1898.

56 En este sentido, véase Di Stefano: El púlpito y la plaza...

57 El Nacional, 9 de diciembre de 1856. 
religiosa un cierto grado de "solemnidad" y un carácter extraordinario. ${ }^{58}$ En un contexto por lo demás festivo, la visita de la autoridad eclesiástica podía en los pueblos de campaña contribuir a las obras del templo dado que su presencia — se esperaba- incentivaría a los fieles a realizar contribuciones y limosnas extraordinarias; ${ }^{59}$ el arzobispo podía además ejercer presión sobre la Municipalidad para emprender determinadas obras cuando las iniciativas del párroco y de un grupo de vecinos no se hallaban acompañadas por el municipio local. Así ocurrió en el pueblo de Moreno cuando el arzobispo lo visitó para la fiesta patronal, según nos relata un vecino: el canónigo Milcíades Echagüe, que acompañaba al arzobispo Aneiros, se dirigió "a los señores municipales representándoles sus deberes para con el templo", ${ }^{60} \mathrm{y}$ su pedido se vio acompañado por los principales vecinos de la localidad, en un almuerzo que el párroco organizó en honor de los visitantes. ${ }^{61}$

Más todavía: las asociaciones de vecinos que, según vemos, juegan un papel tan activo en la construcción de la Iglesia, son capaces de ir aún más lejos en su participación en la vida de la institución eclesiástica. Por ejemplo, los laicos tenían frecuente participación en la liturgia: se formaban coros de niñas y jóvenes que por lo general ocupaban las primeras filas en las funciones religiosas y, por supuesto, atraían al templo a sus familiares y allegados; ${ }^{62}$ podía además incluso organizarse la interpretación de obras musicales en el interior del templo incorporando instrumentos de participación poco habitual en la liturgia como podría ser el arpa, el violín o el piano, que acompañaban las voces de las mujeres. ${ }^{63}$ Ello transcurría así en

58 En 1878 la ausencia del arzobispo a la fiesta patronal del pueblo de Mercedes fue compensada por la visita del jesuita Camilo Jordán, "renombrado orador sagrado", cuya presencia resultaba capaz de convertir a la fiesta en un "verdadero acontecimiento", con la presencia de "no menos de diez mil visitantes", según auguraba La América del Sud, 12 de septiembre de 1877.

59 En Bragado, las contribuciones de los fieles se incrementaron gracias a la visita de Escalada durante la década de 1850, véase al respecto Moya: Contribución a la..., pág. 170.

60 "Carta" de un vecino de Moreno, La América del Sud, 9 de octubre de 1877.

61 Los ejemplos en este sentido podrían multiplicarse: en 1876 el arzobispo aprovechó la visita pastoral para pedir a los vecinos "que ayuden a la Municipalidad a aprontar recursos para que se construyan unos altares" ("Santa visita pastoral", El Católico Argentino, 7 de agosto de 1876); a fines de siglo el provisor Espinosa hacía algo parecido en sus diversas visitas pastorales, a nombre de Aneiros: "mucho hemos recomendado a las autoridades y al pueblo la iglesia que tanta falta hace, y cuya construcción exige tantas consideraciones religiosas y sociales", "Informe de visita y misión en Olavarría", La Voz de la Iglesia, 20 de febrero de 1892.

62 "Notable fiesta", La América del Sud, 6 de junio de 1876.

63 "Sabemos que el señor cura Carranza [de la parroquia de Belgrano] ha hecho muchos preparativos y al efecto se ha empeñado con algunas señoras respetables de la localidad con el objeto de que canten los versos a María [...] y nos consta [...] que se han reunido y ensayado en el arpa y piano para dar mayor realce y esplendor a la fiesta", "Mes de María en Belgrano", La América del Sud, 11 de noviembre de 1876. 
Buenos Aires, a pesar de que la Congregación de Ritos de la curia romana hacía tiempo que recomendaba la difusión del canto gregoriano y su enseñanza en los seminarios, según las disposiciones pontificias... ${ }^{64} \mathrm{La}$ activa participación de los vecinos en la vida cotidiana del templo parroquial los introdujo en otras áreas aún más delicadas todavía: por un lado, no tardaron en presionar sobre el arzobispo para que éste nombrara un párroco de su preferencia. Ya hemos indicado más arriba el caso de los vecinos de Barracas al Sud que reclamaban un presbítero que hablara vasco; asimismo, los vecinos de Balvanera se dirigieron al arzobispo en 1881 para solicitarle que su párroco fuera designado canónigo honorario y, más tarde, los mismos feligreses de Balvanera solicitaron en 1892, con nombre y apellido, que fuera designado párroco Ángel Brasesco que era hasta entonces el teniente cura de la parroquia, y en efecto el arzobispo terminó cediendo al reclamo de los vecinos. ${ }^{65}$ Más aún, las asociaciones de vecinos no vacilaron en ciertos casos en reclamar la facultad de decidir las designaciones de los párrocos, dado que consideraban que tenían derecho a ello; ${ }^{66}$ incluso hubo casos en los que llegaron al punto de exigir la destitución de un clérigo cuando éste les desagradaba, por motivos diversos, por ejemplo, que el párroco no favoreciera a una determinada asociación vecinal. ${ }^{67}$ Cuando ello ocurría, el párroco era enviado a Buenos Aires, se nombraba mientras tanto un clérigo provisorio, y si bien al párroco cuestionado generalmente se lo declaraba absuelto, era común que se lo mudara de curato.$^{68}$ El arzobispo Aneiros tuvo que enfrentar varios casos de este tipo, sin invocar en ninguna ocasión la autoridad romana, o la independencia de la Iglesia con respecto al orden temporal; por el contrario, atendió los reclamos y trató de buscar una salida "negociada" a los incidentes.

64 Un breve de Pío IX de 1873 ponía énfasis en la necesidad de universalizar en todas las diócesis el canto gregoriano. Se halla transcripto en "Canto gregoriano", El católico argentino, 2 de enero de 1875 .

65 "Para cura de Balvanera", La Buena Lectura, 6 de febrero de 1892, donde se reproduce una nota dirigida por los vecinos al arzobispo Aneiros. Ver también la petición elevada por los vecinos en 1881, reproducida en "Reseña histórica del templo parroquial N. S. de Balvanera", Revista eclesiástica del arzobispado de Buenos Aires, 1934, pág. 10 y ss.

66 La Municipalidad de Dolores propuso que se estableciera la libre elección de los párrocos por parte de los vecinos de los pueblos de campaña. Véase Roncoroni, Atilio: Historia del municipio de Dolores, Municipalidad de Dolores, 1967, vol. 2, pág. 47.

67 En 1886 por ejemplo los vecinos del pueblo de Ayacucho tenían en mente impulsar la destitución su párroco. Véase "El cura de Ayacucho", La Voz de la Iglesia, 30 de julio de 1886.

68 Una reseña del conflicto de 1871que tuvo lugar en torno al párroco de en San Nicolás que terminó por ser trasladado - se halla en De la Torre, José E.: Historia de San Nicolás de los Arroyos, Rosario, 1947, pág. 399-400. 
Nos resta todavía analizar una de las manifestaciones más claras de la estrecha relación existente entre los vecinos y la Iglesia: la prensa.

No insistiremos aquí en poner de relieve el importante despliegue de la prensa porteña luego de la caída de Rosas, que ya ha sido abundantemente estudiado ${ }^{69}$ nos interesa más bien estudiar la prensa católica y las relaciones que tiene tanto con la sociedad como con la institución eclesiástica, dado que funciona de bisagra entre ambas. Sin embargo no abordaremos aquí el mundo de las "ideas" que se reproducen en la prensa católica de la segunda mitad del siglo XIX ni nos interesa tampoco estudiar la prensa como "arma de combate" en su lucha contra el "liberalismo"; 70 trataremos de indagar, en cambio, quiénes son los destinatarios y los interlocutores de esta prensa. Como veremos, ellos son múltiples y comprenden desde las comisiones vecinales que participan directamente de la vida de la parroquia hasta la feligresía entendida en un sentido amplio; desde los párrocos hasta el arzobispo y también la municipalidad e incluso, aunque sólo sea por defecto, el gobierno.

Era usual que los párrocos recurrieran a la prensa para publicar la lista de los vecinos y demás feligreses que habían contribuido para una determinada obra en el templo; de este modo el clérigo demostraba su agradecimiento hacia su feligresía y los apellidos de los contribuyentes se veían reflejados en el propio periódico. A veces podía tratarse de apellidos importantes, como ocurrió con la refacción del órgano de la iglesia metropolitana, que incluía a los Anchorena, Elortondo, Llavallol, Guerrico, entre otros. ${ }^{71}$ La propia prensa consideraba que la publicación de los nombres era una forma de honrar a los vecinos que más generosamente contribuían con la construcción de la Iglesia: así, en 1879 se los publicaba "como un homenaje a las distinguidas personas que forman la comisión de la obra del templo". ${ }^{72}$ Estas listas tienen una particularidad: pueden ser interminables e incluso crecen con el correr de los días, dado que a medida que se van publicando las primeras suscripciones, se reciben nuevas, que a su vez se publican incrementando las listas y por supuesto las donaciones obteni-

69 Véanse los trabajos de Hilda Sábato citados más arriba. También, Lettieri, Alberto: "De la república de la opinión a la república de las instituciones", Capitalismo, Estado y orden burgués (18521880), Nueva Historia Argentina, Sudamericana, Buenos Aires, 1999, vol. IV, págs. 97-160.

70 Las "ideas" han sido estudiadas, entre otros, por Auza, Néstor Tomás: Católicos y liberales en la generación del ochenta, Buenos Aires, 1975 (en especial, cap. VIII).

71 "Donativos obtenidos", El católico argentino, 12 de septiembre de 1874.

72 Sin título, La América del Sud, 12 de febrero de 1879. 
das $;^{73}$ de tal modo bien podría pensarse que esta recurrente publicación de listas es una espiral que se alimenta mutuamente: unos colaboran cuando advierten que otros lo han hecho, y de este modo un gran número de apellidos termina por aparecer en el periódico. Incluso el propio periódico podía llegar al punto de sorprenderse de que esto sucediera. En $1877 \mathrm{La}$ América del Sud declaraba que "los fieles de Carmen de Areco parece que rivalizaran en generosidad para con la Casa del Señor". ${ }^{74}$ En definitiva: nadie quería quedar fuera.

En otros casos, se utilizaba la prensa para solicitar la colaboración (económica o en especies) del vecindario para la obra de un templo; las comisiones de vecinos recurrían a la prensa y publicaban avisos para solicitarle a los fieles que colaboraran en lo que les fuera posible: por ejemplo, "debiendo procurarse los recursos necesarios para levantar una pequeña iglesia en honor de la Santísima Virgen del Carmen en el Monasterio de Carmelitas descalzas se suplica a las personas piadosas quieran enviar algunos objetos para ser rifados en beneficio del templo [...] [firma] La Comisión". ${ }^{75}$ La prensa de una determinada parroquia podía incluso tomarse la libertad de solicitar contribuciones para sí, es decir, para una determinada obra en su propio templo; así, el párroco de la Merced se dirigía directamente a su feligresía a través de su periódico parroquial La Buena Lectura en los siguientes términos: "El infrascripto [el cura Antonio Rasore] interpretando los justos anhelos del vecindario desea que las obras de pintura del interior del templo estén terminadas para la fiesta de nuestra gloriosa titular, mas para ello sería necesario que los suscriptores tuviesen a bien abonar su suscripción adelantada hasta diciembre próximo inclusive". ${ }^{76}$ Una apelación tan directa como ésta sólo era posible en una parroquia como la de La Merced que no sólo era próspera, sino que además contaba entre su feligresía a importantes familias de élite, entre ellas, los Anchorena. ${ }^{77}$ De tal modo que la prensa será una herramienta insustituible

73 El 2 de febrero de 1877 La América del Sud publicaba la "primera lista de las personas que hasta la fecha se han suscripto a la obra del altar en honor de la Virgen de Lourdes". Claro que a ésta le seguirán otras.

74 "Más donativos", La América del Sud, 3 de julio de 1877.

75 Aviso, La América del Sud, 7 de octubre de 1877, pág. 3. Los avisos son recurrentes. En la campaña ocurría algo similar, sólo que en estos casos era la prensa local la que reflejaba este tipo de solicitudes. Véase por ejemplo el artículo "La Verdad" de Rojas que es reproducido en la ciudad por La Voz. de la Iglesia, donde se solicitan recursos para la obra del templo, 13 de enero de 1892 ("La iglesia").

76 "Las pinturas de la iglesia de la Merced", La Buena Lectura, 11 de agosto de 1894.

77 Garrigós, Zelmira: Memorias de mi lejana infancia (el barrio de La Merced), San Pedro, Buenos Aires, 1964; Sanguinetti, Manuel Juan, Antonio Rasore, Buenos Aires, 1951. 
para la construcción de la Iglesia; y cuanto más importante era la obra en cuestión, más habrá de advertirse su significación. Por ejemplo, cuando se puso en marcha la construcción de la basílica de Luján —uno de los templos más importantes construidos en la segunda mitad del siglo XIX-, se lanzó una publicación llamada La Perla del Plata que servía entre otras cosas para solicitar donativos y publicar los nombres de aquellos que se hubieran acercado al santuario a contribuir con su óbolo. ${ }^{78}$

Pero la apelación a los vecinos no se limitaba simplemente a reclamar su contribución. La prensa podía estimular a los vecinos a participar activamente en la vida de la institución eclesiástica. Así ocurrió en 1883, cuando el periódico La Unión le recomendó a los vecinos de San Nicolás de los Arroyos que reclamaran que su párroco fuera designado canónigo honorario, título que, según estimaba el periódico, era merecido con creces por el cura: "La población de San Nicolás que conoce los relevantes méritos de su digno cura debería levantar su voz y exigir para su párroco, peticionando a quien corresponda, el título de canónigo honorario que bien merecido y conquistado lo tiene". Era por lo demás frecuente que la prensa juzgara si un determinado cura tenía o no las condiciones para ser promovido, y que opinara acerca de la justeza de los nombramientos efectuados por la curia eclesiástica. ${ }^{79} \mathrm{Y}$, en efecto, tiempo después los vecinos de San Nicolás se dirigieron al arzobispado para reclamar este nombramiento, según publicaría con regocijo el mismo periódico ${ }^{80}$.

Más aún, la prensa también podía ser utilizada para apelar a que la Municipalidad interviniera y tomara medidas cuando un templo sufría deterioros. En 1877 La América del Sud advertió que la capilla del Carmen requería reformas e increpó a la Municipalidad para que pusiera manos en el asunto dado que "esto es grave, muy grave"; pocos días después el mismo periódico informó que la Municipalidad ya estaba al tanto del problema y había tomado las primeras medidas al respecto. ${ }^{81}$ Otro ejemplo en el cual la Municipalidad es la destinataria ocurría también en la ciudad:

78 El 6 de enero de 1890 se lanzaba ese periódico cuyo primer número decía que reproduciría "el movimiento de peregrinos y visitantes al santuario de Luján; las ofrendas en metálico u objetos", Presas, Juan Antonio: Anales de Nuestra Señora de Luján: trabajo histórico-documental 1630-1982, Morón, 1983, pág. 207.

79 Véase por ejemplo un titular que publicaba La Voz de la Iglesia: "Nuevo cura de Chivilcoy. Un nombramiento justo y acertado", 13 de abril de 1893.

80 Sobre el pedido de los vecinos de San Nicolás y la exhortación que al respecto hizo la prensa véase La Unión, 5 de abril de 1883 y 20 de diciembre de 1884.

81 “Capilla del Carmen”, La América del Sud, 20 y 24 de junio de 1877. 
"hacemos notar al Sr. Inspector Municipal de la parroquia de Monserrat que en ella y a una cuadra de un templo y media de una escuela habitan ciertas personas cuya conducta no habla muy a favor de la moral ni de la decencia. Por ahora le hacemos este recuerdo reservádonos para otra vez en caso de que el escándalo siga". ${ }^{82}$ En cambio, la relación con el Estado era sin embargo más difícil, y rara vez se apelaba a él; en la álgida década de 1880, la prensa católica, lejos de denunciar el desinterés del Estado por ocuparse del mantenimiento y reformas de los templos y exigir una intervención más decidida, directamente afirmaba que prescindiría de toda apelación al Estado: "llamamos la atención de los católicos sobre las obras de ensanche y embellecimiento que se están efectuando en el templo de Santo Domingo [...] nuestros actuales gobernantes olvidan sus deberes de argentinos y reniegan de los de católicos. No queda sino el pueblo, a él nos dirigimos" $"$.

En estas iniciativas la prensa no actuaba, sin embargo, como simple vocera de la autoridad eclesiástica. Ninguno de los periódicos católicos del período se halla bajo la directa dependencia del titular de la sede eclesiástica porteña, sino que la mayoría de las veces los periódicos se hallaban administrados por laicos (así el caso de El católico argentino, La América del Sud —en este último participaba Santiago Estrada- y La Unión); siquiera La Voz de la Iglesia se hallaba bajo la administración directa del arzobispado, sino que era el cabildo eclesiástico porteño el que lo dirigía. La prensa católica, incluso, se desarrolló en el seno de las comunidades étnicas de origen inmigratorio: en este sentido puede por ejemplo mencionarse el periódico The Southern Cross de la comunidad irlandesa o la publicación de los italianos, Cristoforo Colombo. ${ }^{84}$

Ello no significa que, en la práctica, el arzobispo no tuviera una influencia decisiva en cada uno de los periódicos católicos, sí la tenía, y de hecho las circulares de la curia dirigidas a los párrocos de ciudad y campaña se publicaban cotidianamente en los periódicos, así como cualquier otro documento emitido por el arzobispado. Pero el arzobispo podía a su vez ser interpelado por la prensa católica, ésta no era simplemente una herramien-

82 La América del Sud, 5 de junio de 1878.

83 "El templo de Santo Domingo", La Voz de la Iglesia, 13 de enero de 1886.

84 Acerca de los irlandeses, véase Korol, Juan Carlos y Sábato, Hilda: Cómo fue la inmigración irlandesa en la Argentina, Buenos Aires, 1981; sobre los italianos: Fernando Devoto, "Catolicismo y anticlericalismo en un barrio italiano de Buenos Aires (La Boca) en la segunda mitad del siglo XIX", Estudios Migratorios Latinoamericanos, 14, 1990, págs. 182-210. 
ta de adoctrinamiento o "disciplinamiento" por parte de la autoridad eclesiástica. Por ejemplo, en 1876 la prensa católica se tomaba la libertad de sugerirle al arzobispo que promoviera a un sacerdote que gozaba de mucho predicamento en el curato en el que oficiaba de teniente cura; sin ningún prurito el periódico indicó que el teniente cura de Mercedes "es muy digno de estar al frente de un curato y lo recomendamos a la consideración del Señor Arzobispo" ${ }^{85}$ Asimismo, en 1886 La Unión reclamaba que el arzobispo se ocupara de atender el reclamo de los vecinos de un curato de campaña que hacía casi un año que permanecía vacante..$^{86} \mathrm{La}$ prensa católica tenía, pues, autonomía con respecto a la cabeza de la Iglesia porteña.

En un contexto donde el papel del Estado ha sido más bien débil en lo que hace a la la construcción de la Iglesia de Buenos Aires, donde las asociaciones vecinales y las municipalidades gozaban de una participación activa en la vida de la Iglesia — en especial a nivel parroquial— y donde la prensa reflejaría esta participación de tal modo que es difícil considerarla como un simple mecanismo de adoctrinamiento por parte de la autoridad eclesiástica, la imagen de la Iglesia que obtenemos resulta en más de un sentido bastante difícil de recortar con respecto a una sociedad a la que la Iglesia se le parece profundamente. A tal punto los vecinos se involucran en la vida "eclesiástica", que desean ser ellos quienes decidan quién será su párroco; y en este contexto, el cura, por su parte, muchas veces participa en asuntos que escapan de la esfera de lo "religioso", según hemos ya indicado. Hubo párrocos que advirtieron esto con suma claridad, en repudio de una concepción de la identidad sacerdotal que le atribuía al cura la "simple" tarea de administrar los sacramentos. Así como los laicos participaban de la gestión de los "asuntos eclesiásticos" interviniendo en la construcción de las iglesias, un párroco de campaña reclamaría "que el sacerdote es ciudadano y que alguna parte ha de concedérsele en la gestión de los asuntos públicos [...] Se quiere al sacerdote encerrado en el templo [...] pero es destruir la esencia de las cosas" ${ }^{87}$ No es azaroso, en este sentido, que encontremos párrocos que ocupen puestos en las municipalidades de campaña; entre ellos se destaca sin duda el caso del cura de San Isidro, Diego Palma, que ocupó durante cerca de treinta años aquel curato, no es casual que

85 "Mercedes", La América del Sud, 2 de abril de 1876.

86 Se trata del curato de Suipacha. Véase "En Suipacha", La Unión, 25 de septiembre de 1886.

87 "La misión del clero", carta de un cura de campaña que firma con las iniciales J. R. Q. (se trataría presumiblemente del cura de Quilmes José Ramón Quesada), La América del Sud, 8 de marzo de 1876. 
Antonio Rasore en La Buena Lectura lo llamara el "patriarca de San Isidro". ${ }^{88}$ Por su parte, el párroco de San Juan Evangelista, el salesiano Esteban Bourlot, era proclamado candidato para las elecciones municipales de 1896, por parte de un grupo de vecinos que se "han reunido en comité" ${ }^{89}$ En estas condiciones, en fin, consideramos que la tesis de la romanización no permite explicar las particularidades del proceso de construcción de la Iglesia en el cual, creemos, jugó un papel decisivo la sociedad, en especial en Buenos Aires.

Recibido el 15 de julio de 2004 Aceptado el 10 de marzo de 2005

88 "El presbítero don Diego Palma", La Buena Lectura, 13 de septiembre de 1890. Véase al respecto de este párroco Actis: Historia de la parroquia... , pág. 211 y ss.

89 "Esteban Bourlot", La Voz de la Iglesia, 9 de noviembre de 1896. Acerca de este párroco puede véase Belza, Juan: En la boca del Riachuelo; Devoto, Fernando: Estudios sobre emigración italiana a la Argentina en la segunda mitad del siglo XIX, Napoli, 1991. 